\title{
ANALISIS PELAKSANAAN PROGRAM PENINGKATAN MUTU PENDIDIK DI SEKOLAH DASAR ISLAM TERPADU AL-FIKRI ISLAMIC GREEN SCHOOL PEKANBARU
}

\author{
Samsul Rizal ${ }^{1}$ \\ Isjoni $^{2}$ \\ Azhar $^{2}$ \\ ${ }^{1}$ Post Graduate Student of Riau University \\ ${ }^{2}$ Lecturer of Education Management Study Programme PPs University of Riau
}

\begin{abstract}
The main objective of this research was reveal in detail by facts and data to get a complete image about the implementation of improvement program of educator quality at integrated elementary school Al-Fikri Islamic Green School Pekanbaru. This research specifically aimed reveal information objectively and empirically that relates understanding of improvement program of teachers' quality, implementation of improvement program types, the supporting and abstracting factors in the implementation of the program and the effects of the implementation of the program at integrated elementary school Al-Fikri Islamic Green School Pekanbaru. This research used qualitative approach; the data were collected by interview, observation, and documentation. The data were analyses by descriptive qualitative with descriptive presentation, and triangulation was used know the data validity. The result showed that the teachers understand the improvement program of the teacher quantity well. The improvement programs of teachers' quality at this school which were actualized in some programs such as education and training, ta'lim, kkg, teacher meeting, supervision, seminars workshop, study tour, character school programs could be done well. It was showed that there were supporting and obstructing factors on this program. Then, this program had positive effect toward the development of teacher competence optimally, positive effect an teacher service students, positive effect an teacher service to students' parents, and positive effect an school quality.
\end{abstract}

Key words: Improvement, quality, teacher, continuously

\begin{abstract}
Abstrak: Peningkatan mutu guru selalu menjadi prioritas, karena upaya ini didasari alasan bahwa indikator utama keberhasilan sekolah adalah kemampuan melaksanakan kegiatan belajar mengajar secara aktif, kreatif, efektif, dan menyenangkan.Tujuan utama penelitian ini adalah untuk mengungkap secara detail dengan fakta dan data untuk memperoleh gambaran lengkap tentang pelaksanaan program peningkatan mutu guru di Sekolah Dasar Islam Terpadu Al-Fikri Islamic Green School Pekanbaru. Secara spefisik penelitian ini bertujuan untuk mengungkapkan informasi secara objektif dan empirik yang berkaitan dengan pemahaman program peningkatan mutu guru, keterlaksanaan jenis program peningkatan mutu guru, faktor-faktor pendukung dan penghambat dalam pelaksanaan program peningkatan mutu guru dan dampak pelaksanaan program peningkatan mutu guru di Sekolah Dasar Islam Terpadu Al Fityah Pekanbaru. Menggunakan pendekatan kualitatif, Teknik pengumpulan data pada penelitian ini melalui wawancara, observasi, dan dokumentasi. Analisis data adalah deskriptif kualitatif dengan penyajian secara deskriptif, dan untuk keabsahan datanya menggunakan triangulasi. Hasil dari penelitian ini diperoleh gambaran bahwa. Program peningkatan mutu guru di Sekolah Dasar Islam Terpadu Al-Fikri Islamic Green School Pekanbaru yang diaktualisasikan dalam beberapa program diantaranya pendidikan dan pelatihan, ta'lim rutin guru, KKG, rapat guru, supervisi, seminar, workshop, studi banding, serta program sekolah berkarakter dapat terlaksana dengan baik. Terungkap bahwa terdapat faktor-faktor pendukung dan penghambat dari pelaksanaan program ini. Kemudian
\end{abstract}


JURNAL

MANAJEMEN PENDIDIKAN

Vol. 5 No.1 Maret 2021: pp.1-10

PENELITIAN KUALITATIF

e-ISSN: 2775-6904 | p-ISSN: 2502-9487

Program peningkatan mutu guru ini mempunyai dampak positif terhadap berkembangnya kompetensi guru secara optimal, dampak positif layanan guru terhadap siswa, dampak positif layanan guru terhadap orangtua, dan dampak positif terhadap mutu sekolah.

Kata Kunci: peningkatan, mutu, guru, berkelanjutan

\section{PENDAHULUAN}

Hasil dari pendidikan yang berkualitas sangat kita rasakan secara langsung dalam kehidupan bermasyarakat, kehidupan kelompok dan kehidupan individu.Pendidikan berkaitan langsung dengan proses pembentukan manusianya. Pendidikan menentukan langsung model manusia yang akan dibentuk dan merupakan wahana bagi penerjemahan dan implementasi aturan-aturan yang dibuat dalam kehidupan berbangsa dan bernegara serta bermasyarakat. Masyarakat yang cerdas akan memberi nuansa kehidupan yang cerdas pula, dan secara otomatis mampu membentuk kemandirian dan kreativitas. Oleh karenanya pembangunan pendidikan menjadi sebuah prioritas dalam upaya mewujudkan sumber daya manusia yang berkualitas. Pendidikan menjadi barometer kemajuan suatu bangsa dan oleh karenanya kebijakan pemerintah dalam pendidikan mengacu kepada suatu upaya strategi pencapaian tujuan pendidikan nasional.

Undang-Undang Republik Indonesia nomor 20 tahun 2003 tentang Sistem Pendidikan Nasional (UU Sisdiknas) merumuskan fungsi dan tujuan pendidikan nasional yang harus digunakan dalam mengembangkan upaya pendidikan di Indonesia. Pasal 3 UU Sisdiknas menyebutkan, Pendidikan Nasional berfungsi mengembangkan dan membentuk watak serta peradaban bangsa yang bermartabat dalam rangka mencerdaskan kehidupan bangsa, bertujuan untuk berkembangnya potensi peserta didik agar menjadi manusia yang beriman dan bertakwa kepada Tuhan Yang Maha Esa, berakhlak mulia, sehat, berilmu, cakap, kreatif, mandiri, dan menjadi warga negara yang demokratis serta bertanggung jawab". Tujuan pendidikan nasional itu merupakan rumusan mengenai kualitas manusia Indonesia yang harus dikembangkan oleh setiap satuan pendidikan.Oleh karena itu, rumusan tujuan pendidikan nasional menjadi dasar dalam pengembangan pendidikan budaya dan karakter bangsa.

Secara umum, kualitas sumber daya insani (manusia) yang dibutuhkan adalah yang memiliki kualitas tinggi dalam iman dan taqwa (moral), pola pikir, proses kerja, hasil karya dan akhirnya menghasilkan nilai tinggi dalam kualitas hidup. Secara khusus dibutuhkan sumber daya insani yang memiliki loyalitas yang tinggi (sense of ownership), yang memiliki kreatifitas, penuh inovasi, bertanggung jawab, jujur, ambisi pada prestasi dan disiplin. Itulah pribadi-pribadi tangguh yang memiliki interpersonal skill yang tinggi dan senantiasa mampu bersinergi dalam siasat jitu, agar mampu survive dan keluar sebagai pemenang. Sumber daya Insani ini hanya dapat lahir dari sebuah institusi pendidikan yang betul-betul dikelola secara baik dan profesional.

\section{METODOLOGI PENELITIAN}

\section{Jenis Penelitian}

Pendekatan yang digunakan dalam penelitian ini adalah pendekatan kualitatif. Dalam penelitian ini, peneliti mengadakan penyelidikan untuk mengungkap data dan fakta yang sedang terjadi dari subjek penelitian berkenaan dengan rumusan masalah yang telah dikemukakan. Penelitian kualitatif sering disebut metode penelitian naturalistik karena penelitian dilakukan dalam kondisi yang alamiah (natural setting).

\section{Tempat dan Waktu Penelitian}

Peneliti mengambil lokasi penelitian di Sekolah Dasar Islam Terpadu Al-Fikri Islamic Green School Pekanbaru yang beralamat di J1. Merak, No. 1 Tangkerang Tengah, Marpoyan Damai, Pekanbaru. Waktu yang digunakan untuk penelitian ini adalah mulai terhitung sejak studi pendahuluan tanggal 01 Februari 2017 sampai dengan tanggal 05 Agustus 2017. 
JURNAL

MANAJEMEN PENDIDIKAN

Vol. 5 No.1 Maret 2021: pp.1-10

PENELITIAN KUALITATIF

e-ISSN: 2775-6904 | p-ISSN: 2502-9487

\section{Teknik Pengumpulan Data}

Jenis data yang diungkapkan dalam penelitian ini adalah bersifat skematik, narasi, dan uraian juga penjelasan data dari informan baik lisan maupun data dokumen yang tertulis, perilaku subjek yang diamati di lapangan juga menjadi data dalam pengumpulan hasil penelitian ini, dan berikutnya dideskripsikan sebagai berikut.

1. Observasi

2. Dokumentasi

3. Wawancara

\section{Teknik Analisis Data}

Teknik analisis data yang digunakan adalah deskriptif kualitatif dimana setelah data yang diperlukan terkumpul, peneliti melakukan analisa data dengan menggunakan langkah-langkah seperti yang dikemukakan Milles dan Huberman yang secara umum terdiri dari empat alur kegiatan, yaitu:

1. Pengumpulan data, 2. Reduksi data, 3. Penyajian data, 4. Menarik kesimpulan/verifikasi.

\section{HASIL DAN PEMBAHASAN}

Pelaksanaan program peningkatan mutu pendidik di Sekolah Dasar Islam Terpadu Al-Fikri Islamic Green School Pekanbaru

Diantara jenis program yang dilaksanakan oleh Sekolah Dasar Islam Terpadu Al-Fikri Islamic Green School Pekanbaru adalah :

1. Pendidikan dan Pelatihan (DIklat)

Peningkatan kompetensi guru dapat dilakukan melalui program pelatihan dalam jabatan (in service training). Pelatihan mengandung makna bahwa setelah mengikuti pelatihan guru akan terdorong motivasinya untuk memperbaiki kinerja, cara pembelajaran atau penyegaran ilmu dan informasinya. Pelatihan secara umum diartikan sebagai kegiatan untuk memperbaiki penguasaaan berbagai ketrampilan dan teknik pelaksanaan kerja tertentu dalam waktu yang sangat singkat.

Program ini dilaksanakan di Sekolah Dasar Islam Terpadu Al-Fikri Islamic Green School Pekanbaru secara rutin, dan setiap guru mendapatkan giliran 1 pekan sekali. Program pelatihan ini dilakukan dengan tujuan :

\section{Meningkatkan kualitas Sumber Daya Manusia (SDM)}

Para pendidik yang bekerja atau didayagunakan oleh Sekolah senantiasa meningkat kompetensinya. Hal ini diharapkan dapat mendukung target sekolah dalam upaya mencapai sasaran yang telah ditetapkan. Bekerja sesuai Misi dan Visi sekolah.

\section{Menciptakan interaksi antara guru}

Dengan waktu yang padat dengan sistem fullday school, antar guru yang satu dengan yang lain interaksi sedikit berkurang, ditambah lagi masing-masing guru di SDIT Al-Fikri Islamic Green School Pekanbaru tidak duduk dan berkumpul di ruang guru ketika tidak mengajar, namun duduk di kelas (berkantor di kelas) masing-masing. Dengan pengalaman dan latar belakang yang berbeda-beda mereka dapat saling sharing dalam pelatihan. Kendala-kendala yang dialami selama proses pembelajaran dapat langsung mendapatkan solusi dari rekan-rekan yang lainnya, hal Ini lebih meringankan beban para pendidik.

\section{Mempererat rasa kekeluargaan dan kebersamaan antara Pendidik.}

Karena mereka bekerja untuk satu naungan yang sama, bukan tidak mungkin mereka tidak lagi kaku untuk sharing, bersahabat dan lebih kompak.

Meningkatkan motivasi dan budaya belajar yang berkesinambungan.

Dalam melakukan program training ini, Divisi diklat yang dipercaya oleh SDIT Al-Fikri Islamic Green School Pekanbaru melakukan tahapan-tahapan kegiatannya yaitu:

1. Melaksanakan Identifikasi Kebutuhan pelatihan 
JURNAL

MANAJEMEN PENDIDIKAN

Vol. 5 No.1 Maret 2021: pp.1-10

PENELITIAN KUALITATIF

e-ISSN: 2775-6904 | p-ISSN: 2502-9487

Ini dilakukan untuk memperoleh gambaran tentang masalah-masalah yang dihadapi oleh para guru di sekolah, survey dilakukan melalui wawancara dan juga pengisian form. Contoh masalah-masalah yang sering muncul adalah : guru masih belum mempunyai pemahaman yang baik tentang kondisi murid-murid mereka, guru masih kaku dalam menghadapi murid, guru kurang kreatif, para tenaga kependidikan kurang ramah dalam menghadapi pelanggan (orangtua atau siswa), guru masih mengajar dengan menggunakan pola atau model lama, dll.

2. Menentukan Kebutuhan Training

Setelah mendapatkan gambaran tentang masalah-masalah yang muncul di lapangan selanjutnya dilakukan penentuan apa materi yang menjadi kebutuhan bagi para guru agar mereka lebih baik.

3. Desain Pelatihan

Dengan cara apa kira-kira materi tersebut kita berikan, melalui presentasi, diskusi, simulasi, workshop, dll. Berapa durasi yang kita alokasikan untuk memberikan materi tersebut? 1 sesie 2 sesie atau berapa? Siapa saja yang harus mengikuti? Setelah itu barulah kita mendesain bentuk pelatihan yang sesuai dengan kebutuhan lembaga atau sekolah. Dalam hal ini juga disusun jadwal dan agenda training. disesuaikan dengan jam mengajar guru.

Berbagai model pelatihan yang telah dilaksanakan oleh internal SDIT Al-Fikri Islamic Green School Pekanbaru yang dilakukan setiap hari sesuai jadwal adalah sebagai berikut:

a. Training Peningkatan mutu Pendidik dan Tenaga Kependidikan

b. Sekolah Murabbi

2. Program Ta'lim Pekanan

3. Kelompok Kerja Guru (KKG)

4. Rapat Sekolah

5. Workshop

6. Seminar

7. Supervisi

8. Studi Banding

9. Program Sekolah Berkarakter

Faktor-faktor pendukung dan penghambat dalam pelaksanaan program peningkatan mutu pendidik di Sekolah Dasar Islam Terpadu Al-Fikri Islamic Green School Pekanbaru

a. Faktor Pendukung

Faktor yang menjadi Pendukung pelaksanaan program peningkatan mutu pendidik di

Sekolah Dasar Islam Terpadu Al-Fikri Islamic Green School Pekanbaru adalah:

1. Guru-guru di SDIT Al-Fikri Islamic Green School Pekanbaru Terseleksi dengan baik dengan rata-rata pendidikan S1 dan masih usia produktif. Dari data-data yang penulis dapatkan dari Bidang Kepegawaian Yayasan Wakaf Islam Al Fikri Riau diperoleh gambaran bahwa guru di SDIT Al-Fikri Islamic Green School Pekanbaru sebagian besar pendidikannya adalah S1. Ini menjadi modal bagi sekolah dalam mengupayakan perbaikan mutu sekolah. Secara keilmuan yang mereka miliki sewaktu mengenyam pendidikan di S1, paling tidak ini secara kompetensi professional para pendidik memiliki wawasan yang cukup memadahi.

2. Komitmen untuk Berkembang Tinggi. Di kalangan para pendidik di SDIT Al-Fikri Islamic Green School Pekanbaru mulai terbangun suasana bahwa Ilmu itu senantiasa terus berkembang dan menyesuaikan dengan perkembangan zaman. Siapa yang berhenti untuk belajar maka dia akan tertinggal. Mereka juga menyadari bahwa untuk mencapai sebuah kesuksesan perlu usaha dan kerja dengan semangat. Sebuah semboyan "Mutu atau Mati "menjadi dorongan agar setiap individu senantiasa mengupayakan perbaikan secara individu dengan senantiasa belajar dan belajar karena jika itu tidak mereka lakukan maka mereka akan tertinggal. Ilmu itu senantiasa berkembang, karakteristik siswa yang dihadapi juga senantiasa berubah, secara otomatis ini juga mempengaruhi metode dan cara kita 
JURNAL

MANAJEMEN PENDIDIKAN

PENELITIAN KUALITATIF
Vol. 5 No.1 Maret 2021: pp.1-10

e-ISSN: 2775-6904 | p-ISSN: 2502-9487

untuk menyampaikannya. Dengan mengikuti program peningkatan mutu pendidik ini guruguru mendapatkan pencerahan tentang banyak hal termasuk metode dan cara-cara baru yang hari ini banyak berkembang. Sesuai dengan karakteristik dari kurikulum, bahwa kurikulum dikembangkan atas dasar kesadaran bahwa ilmu pengetahuan, teknologi dan seni berkembang secara dinamis. Oleh karena itu, semangat dan isi kurikulum memberikan pengalaman belajar peserta didik untuk mengikuti dan memanfaatkan perkembangan ilmu pengetahuan, teknologi, dan seni.

3. Terjalin kerjasama yang baik antara pihak yang terkait. Seperti kepala sekolah dan Wakil Kepala Sekolah, guru, dan pengelola Diklat, dan juga penanggung jawab dari masingmasing program termasuk dukungan dari Yayasan sebagai lembaga yang menaungi unitunit sekolah yang ada. Hal ini juga sebuah perwujudan membangun tim work yang baik dalam usaha menciptakan visi sekolah yaitu "Menjadi Model Bagi Lembaga Pendidikan Dasar Islam di Riau Tahun 2018". Kepala Sekolah Dasar Islam Terpadu Al-Fikri Islamic Green School Pekanbaru beserta stafnya merancang program sebagai kepala sekolah berdasar pada 8 Standar sesuai Badan Standar Nasional Pendidikan. Diantara standar itu adalah standar pendidik dan tenaga kependidikan. Salah satu program yang dirancang adalah program peningkatan mutu pendidik dan tenaga kependidikan yang selanjutnya dijabarkan dalam bentuk kegiatan-kegiatan. Hal-hal terkait dengan program yang akan dilaksanakan dibahas dalam rapat rutin sekolah dengan Yayasan dan lembaga yang berada di bawah Yayasan seperti Divisi Diklat. Pertemuan atau rapat itu dinamakan "Rafored" singkatan dari Rapat Forum Edukasi. Forum ini menjadikan komunikasi dan koordinasi dari semua pihak terhadap program-program yang digulirkan baik Yayasan maupun internal sekolah atau antar unit (PAUD, TK, SD, dan SMP) dapat berjalan dengan baik. Tidak ada sumbatan-sumbatan komunikasi. Inilah yang menyebabkan adanya dukungan yang penuh baik dari pihak internal sekolah (Kepala Sekolah, waka dan guru) juga dukungan dari Yayasan sehingga program peningkatan mutu pendidik dan tenaga kependidikan di SDIT Al-Fikri Islamic Green School Pekanbaru dapat berjalan maksimal.

4. Sarana dan prasarana Pendidikan dan Pelatihan yang mendukung. Dari segi sarana dan prasarana untuk program pelatihan guru cukup mendukung (Ruangan Diklat ber AC, LCD Proyektor, Lap Top, Sound System). Dari observasi yang penulis lakukan kondisi ruangan cukup kondusif untuk pelaksanaan program pendidikan dan pelatihan, KKG, Rapat rutin pekanan, Rafored, dan pertemuan lain yang kapasitas pesertanya tidak lebih dari 15 orang. Jika lebih maka solusinnya sekolah harus menggunakan ruang kelas yang bisa terhubung antara kelas yang satu dengan yang lainya, seperti pada pelaksanaan KKG Gugus dengan jumlah peserta lebih dari 30 orang.

5. Nara Sumber/Instruktur dari Internal

Untuk program-program secara rutin setiap pekan seperti pelatihan, Sekolah Murabbi, dan Workshop memanfaatkan para guru SDIT Al-Fikri Islamic Green School Pekanbaru yang telah senior dan telah berpengalaman di berbagai pelatihan dan telah mendapatkan sertifikat sebagai instruktur. Hal ini sangat menguntungkan dari aspek pendanaan. Jika harus mendatangkan instruktur dari luar kemungkinan dibutuhkan dana yang besar apalagi dilakukan setiap hari. Selain itu jika instruktur dari dalam mereka lebih memahami permasalahan internal dari sekolah tersebut, juga memahami karakteristik dari para peserta program peningkatan mutu tersebut. Hal ini justru memaksimalkan tujuan yang ingin dicapai dari program yang dilaksankan. Seperti seorang dokter yang akan mengobati pasiennya, dokter sudah memahami apa yang menjadi penyakit pasiennya dan obat apa yang harus diberikan, ini akan mempercepat kesembuhan dari pasien yang diobatinya.

6. Mempunyai Relasi dengan semua pihak yang terkait dengan kemajuan pendidikan di sekolah. SDIT Al-Fikri Islamic Green School Pekanbaru menjalin relasi dengan sesama sekolah yang tergabung dalam Jaringan Sekolah Islam Terpadu (JSIT) Indonesia, sehingga informasi untuk peningkatan kompetensi guru dapat diakses lebih cepat. Seperti pelatihan kurikulum 2013, Pelatihan Standar Mutu Sekolah, dll. Relasi untuk mendatangkan nara sumber yang berkompeten dari luar yang memahami sekolah Islam terpadu juga lebih 
JURNAL

MANAJEMEN PENDIDIKAN

Vol. 5 No.1 Maret 2021: pp.1-10

PENELITIAN KUALITATIF

e-ISSN: 2775-6904 | p-ISSN: 2502-9487

mudah. Hal ini sesuai dengan motto JSIT Indonesia "Empowering Islamic Schools". Pemberdayaan sekolah-sekolah Islam agar senantiasa mampu meningkatkan mutu pendidikannya. Diantara strategi dan pendekatan yang diterapkan dalam menjalankan misi dan tujuannya pendidikan, dan diharapkan dapat mendukung keefektifan penyelenggaraan sekolah adalah menjalankan kemitraan yang efektif dengan berbagai pihak yang terkait, terutama orangtua siswa dan masyarakat sekitar.

Dampak pelaksanaan program peningkatan mutu pendidik di Sekolah Dasar Islam Terpadu AlFikri Islamic Green School Pekanbaru

Program peningkatan mutu pendidik di Sekolah Dasar Islam Terpadu Al-Fikri Islamic Green School Pekanbaru membawa dampak positif, yaitu :

1) Dampak positif yang dirasakan oleh pendidik adalah meningkatnya motivasi dan semangat kerja, mereka lebih percaya diri, lebih mengerti arti sebagai pendidik, lebih bertanggung jawab dalam tugas dan waktu serta lebih menyayangi dan peduli terhadap siswa juga lebih kreatif dalam mengajar. Selalu ada tempat untuk menyalurkan berbagai kendala mereka dan ditanggapi oleh guru yang lain sehingga guru tersebut mendapat solusi dan dapat melakukan perbaikan secara terus menerus. Para pendidik memiliki wawasan yang luas dan langsung bisa dipraktekkan.

2) Para pendidik dapat menjadi figur contoh bagi peserta didik. Keteladanan akan sangat berpengaruh terhadap hasil belajar. Dan kualitas hasil belajar sangat dipengaruhi oleh kualitas keteladanan yang ditunjukkan oleh para pendidik. Inilah yang telah dilakukan oleh Rasulullah SAW kepada ummatnya, sehingga menghasilkan ummat terbaik. Dan ini pula yang harus dikembangkan oleh setiap lembaga pendidikan agar menghasilkan peserta didik sesuai dengan tujuan yang telah ditetapkan. Artinya ketika sekolah telah menetapkan kedisiplinan dalam kehadiran di sekolah dan kedisiplinan dalam berpakaian bagi peserta didiknya, tentunya yang pertama kali memberi contoh dalam kedisiplinan tersebut hendaknya dimulai dari seluruh pendidik dan tenaga kependidikan. Demikian pula dalam interaksi sehari-hari.

3) Secara terus menerus program peningkatan mutu guru sebagai upaya mengembangkan aspek kompetensi tenaga kependidikan memiliki tujuan agar guru terus berkembang sejalan dengan perkembangan ilmu pengetahuan dan teknologi. Peningkatan mutu guru selalu menjadi yang prioritas, karena upaya ini didasari alasan bahwa indikator utama keberhasilan sekolah adalah kemampuan melaksanakan kegiatan belajar mengajar secara efektif dan efisien sesuai dengan tuntutan kurikulum dan menyiapkan tamatan yang memenuhi kebutuhan pembangunan masa kini dan masa yang akan datang.

4) Peran yang strategis dan merupakan kunci keberhasilan mencapai tujuan kelembagaan sekolah dapat dilakukan oleh guru. Guru adalah pengelola KBM bagi para siswanya. Kegiatan belajar mengajar akan berjalan efektif apabila tersedia guru yang sesuai dengan kebutuhan sekolah baik jumlah, kualifikasi maupun bidang keahliannya.

5) Kompetensi guru seperti yang meliputi kompetensi kepribadian, kompetensi sosial, kompetensi pedagogik dan kompetensi profesional dapat berkembang dengan baik. Ketika dilakukan secara terus menerus, maka para pendidik akan mendapatkan proses perbaikan mutu secara optimal. Guru juga menyadari bahwa apa yang sudah dimiliki jika tidak dikembangkan lagi maka mereka akan tertinggal.

6) Undang-Undang Republik Indonesia Nomor 20 Tahun 2003 tentang Sistem Pendidikan Nasional, telah menyebutkan bahwa jabatan guru sebagai pendidik merupakan jabatan profesional. Untuk itu, guru yang professional dituntut untuk secara terus-menerus pengembangkan diri sesuai dengan perkembangan zaman, ilmu pengetahuan, dan teknologi, serta kebutuhan masyarakat termasuk kebutuhan terhadap sumber daya manusia yang berkualitas dan memiliki kapabilitas untuk mampu bersaing di forum regional, nasional, ataupun internasional.

7) Para pendidik di SDIT Al-Fikri Islamic Green School Pekanbaru telah menunjukkan perwujudan dari berbagai kompetensi yang senantiasa dikembangkan secara terus menerus (continuous improvement). Diantaranya adalah kompetensi kepribadian. Ini ditunjukkan dengan karakteristik guru dalam proses pembelajaran dan proses pendidikan secara umum di sekolah. 
JURNAL

MANAJEMEN PENDIDIKAN

PENELITIAN KUALITATIF
Vol. 5 No.1 Maret 2021: pp.1-10

e-ISSN: 2775-6904 | p-ISSN: 2502-9487

Yang ditunjukkan dengan kemampuan personal yang mencerminkan kepribadian yang mantap, stabil, dewasa, arif, dan berwibawa, menjadi teladan bagi peserta didik, dan berakhlak mulia.

8) Berbagai prestasi yang membanggakan sekolah juga ditunjukkan oleh para guru. Ini sebagai akibat ruang-ruang guru untuk berkreatifitas dan mengembangkan diri untuk kemajuan pendidikan terus diberikan peluang. Berbagai prestasi guru dalam berbagai perlombaan juga diperoleh.

9) Kompetensi yang terlihat berkembang dengan baik adalah kompetensi pedagogik. Kompetensi pedagogik merupakan kemampuan yang berkenaan dengan pemahaman terhadap peserta didik dan pengelolaan pembelajaran yang mendidik dan dialogis. Secara substantif, kompetensi ini mencakup kemampuan pemahaman terhadap peserta didik, perancangan dan pelaksanaan pembelajaran, evaluasi hasil belajar, dan pengembangan peserta didik untuk mengaktualisasikan berbagai potensi yang dimilikinya. Perwujudan dari kompetensi ini ditunjukkan oleh guru seperti hasil observasi penulis, yaitu adanya kreativitas dan penggunaan berbagai metode pembelajaran oleh guru. Guru mampu mengaitkan konten materi dengan dunia nyata. Pembelajaran lebih dekat dengan dunia anak karena banyak yang sifatnya kontekstual dan sangat bersentuhan dengan kehidupan sehari-hari peserta didik.Siswa dengan berbagai potensi mampu diakomodir oleh para pendidik di SDIT Al-Fikri Islamic Green School Pekanbaru.

10) Guru SDIT Al-Fikri Islamic Green School Pekanbaru mempunyai Kompetensi keshalihan sosial yang meningkat dengan ditandai semakin menjadikan profesi pendidik sebagai misi dakwah berbasis pendidikan. Mampu berinteraksi positif dengan siswa, sesama guru, orang tua siswa dan masyarakat sekolah. Mampu berinteraksi positif dengan berbagai pihak dalam rangka meningkatkan profesinya.

11) Kompetensi profesional para pendidik di SDIT Al-Fikri Islamic Green School Pekanbaru meningkat. Ini ditandai dengan semakin meningkatkan kemampuan yang berkenaan dengan penguasaan materi pembelajaran bidang studi secara luas dan mendalam yang mencakup penguasaan substansi isi materi kurikulum mata pelajaran di sekolah dan substansi keilmuan yang menaungi materi kurikulum tersebut, serta menambah wawasan keilmuan sebagai guru. Guru mampu mengeksplorasi pembelajaran dengan baik dan mampu mengaitkan dengan kehidupan nyata dan menjadikan proses pembelajaran bermanfaat secara duniawi dan ukhrawi.

12) Para pendidik di SDIT Al-Fikri Islamic Green School Pekanbaru juga telah dipercaya oleh berbagai lembaga baik lembaga pendidikan maupun non kependidikan, untuk menjadi nara sumber dari berbagai kegiatan pelatihan seperti seminar, workshop, dan berbagai kegiatan lainnya. Ini adalah hasil dari sebuah proses jangka panjang yang menghasilkan peningkatan mutu guru secara terus menerus dan pada akhirnya mereka memiliki kapasitas yang dianggap mampu memberikan kontribusi besar terhadap kemajuan pendidikan secara luas.

13) Dampak yang dirasakan oleh siswa adalah semangat siswa lebih meningkat dalam belajar atau hadir ke sekolah.

14) Prestasi-prestasi tersebut ditunjukkan oleh siswa karena kreativitas siswa dan motivasi berprestasinya sangat tinggi. Kemudian dampak positif terhadap layanan terhadap orangtua adalah komunikasi antara guru dengan orangtua lebih lancar dan lebih baik.

15) Hal ini sesuai dengan karakteristik Kurikulum Sekolah Dasar Islam terpadu Al-Fikri Islamic Green School Pekanbaru, bahwa perlu adanya kerjasama yang sistematis dan efektif antara guru dan orang tua dalam mengembangkan dan memperkaya pendidikan dalam berbagai aneka program.

16) Dampak positif dari program peningkatan mutu pendidik dan tenaga kependidikan terhadap sekolah adalah tingkat pencapaian Quality Assurance (QA) atau jaminan mutu lulusan SDIT AlFikri Islamic Green School Pekanbaru menjadi lebih baik.

17) Ini membuktikan bahwa adanya kepuasan bagi orangtua terhadap layanan pendidikan yang dilakukan oleh para pendidik di SDIT Al-Fikri Islamic Green School Pekanbaru.

18) Dampak positif dari pelaksanaan program peningkatan mutu pendidik secara berkelanjutan (continuous improvement) yang telah dikemukakan di atas dapat menjadi alasan bahwa semua lembaga pendidikan harus melihat bahwa pendidik adalah "Human Capital" yang merupakan aset berharga yang akan memberikan kontribusi besar terhadap ketercapaian tujuan-tujuan 
JURNAL

MANAJEMEN PENDIDIKAN

Vol. 5 No.1 Maret 2021: pp.1-10

PENELITIAN KUALITATIF

e-ISSN: 2775-6904 | p-ISSN: 2502-9487

pendidikan. Continuous improvement adalah peningkatan dan perbaikan yang berkesinambungan (tiada henti) dimana mengarah pada kemajuan yang lebih baik atau unggul.

Penerapan continuous improvement di lembaga pendidikan (sekolah) harus benar-benar diwujudkan.

\section{SIMPULAN}

Berdasarkan hasil dari penelitian yang telah diuraikan, maka dapat penulis rekomendasikan:

1. Kepada Yayasan yang menaungi SDIT Al-Fikri Islamic Green School Pekanbaru bahwa dalam rangka meningkatkan kualitas layanan program peningkatan mutu pendidik dan tenaga kependidikan, serta Sebagai upaya untuk memberikan layanan dan meningkatkan mutu pendidikan di sekolah, agar mengupayakan sarana dan prasarana pendukung program peningkatan mutu seperti adanya aula atau gedung khusus untuk pendidikan dan pelatihan SDM Pendidikan. dan sarana dan prasarana sekolah secara umum seperti Lab IPA, Lab Bahasa, dll.

2. Kepada sekolah, Perlu pengaturan jam mengajar guru yang lebih proporsional dan dapat mengusulkan kepada Yayasan Jika memungkinkan menambah SDM guru.

3. Kepada sekolah perlu melakukan supervisi klinis secara rutin, agar guru dapat selalu ditingkatkan mutunya dan kekurangan-kekurangan yang ia miliki dapat segera diatasi tanpa merasa guru sedang dinilai. Kemudian upaya-upaya peningkatan mutu secara terus menerus dapat diupayakan secara maksimal.

4. Para pengelola dan penanggung jawab program peningkatann mutu pendidik di SDIT Al-Fikri Islamic Green School Pekanbaru hendaknya senantiasa semangat dan tetap menjalankan program meskipun kehadiran peserta tidak maksimal, membuat administrasi dan dokumentasi yang baik,agar dalam perjalanannya dapat senantiasa diperbaiki dan hasilnya maksimal.

5. Pengelola Divisi Diklat Yayasan Wakaf Islam Al Fikri Riau perlu mendesain program pendidikan dan pelatihan yang lebih variatif dan sesuai dengan kebutuhan guru serta perlu menghadirkan narasumber atau instruktur yang berkompeten dari eksternal (luar SDIT Al-Fikri Islamic Green School Pekanbaru) agar lebih bervariasi dan ada hal yang baru didapatkan oleh peserta program peningkatan mutu.

6. Memberikan Reward atau penghargaan terhadap pendidik yang memiliki komitmen yang tinggi dalam mengikuti program peningkatan mutu secara berkelanjutan serta senantiasa berupaya untuk mengembangkan potensinya dan memiliki kinerja yang tinggi.

7. Kepada peneliti selanjutnya, direkomendasikan untuk melakukan penelitian baik kualitatif maupun kuantitatif terkait dengan penelitian manajemen pendidikan yaitu :

a. Implementasi manajemen kelas di SDIT Al-Fikri Islamic Green School Pekanbaru

b. Program pembinaan Karakter Guru di SDIT Al-Fikri Islamic Green School Pekanbaru

\section{DAFTAR PUSTAKA}

Agung, Iskandar. 2014. Mengembangkan Profesionalitas Guru. Jakarta. Bee Media Pustaka.

Arikunto,Suharsimi. 1997. Prosedur Penelitian. Jakarta : Rineka Cipta

Barthos, Basir. 2001. Manajemen Sumber Daya Manusia. Jakarta:Bumi Aksara.

Barkley. 2010. Quality Teaching a Culture of Coaching. New York. Rowman \&Littlefield Publisher.Inc.

Chatib,Munib.2011.Gurunya Manusia. Bandung:Kaifa.

Creswell, Jhon W.2011. Penelitian Kualitatif Bidang Pendidikan.Alih bahasa Prof. Dr. H. M. Diah Z,M.Ed.Pekanbaru : Umri Press. 


\section{JURNAL}

MANAJEMEN PENDIDIKAN

PENELITIAN KUALITATIF
Vol. 5 No.1 Maret 2021: pp.1-10

e-ISSN: 2775-6904 | p-ISSN: 2502-9487

Departemen Pendidikan Nasional., 2005. Undang-Undang No.20 tahun 2003 tentang Sistem Pendidikan Nasional. Jakarta; Biro Hukum dan Organisasi Sekjen Depdiknas

Departemen Pendidikan Nasional., 2005. Undang-Undang No.14 tahun 2005 tentang Undang-undang Guru dan Dosen.

Goetsch, D. L., dan Davis, S. 1994. Introduction to Total Quality: Quality, Productivity, Competitiveness. New Jersey: Prentice Hall Internasional, Inc.

Djamarah, Syaiful Bahri. 2000. Guru dan Anak Didik Dalam Interaksi Edukatif. Jakarta:Rineka Cipta

Fahmy Alaidroes. 2014. Standar Mutu Kekhasan Sekolah Islam Terpadu.Jakarta: JSIT

Hikmat. 2011. Manajemen Pendidikan. Bandung: Pustaka Setia

Isyandi. 2004. Manajemen Sumber Daya Manusia.Riau: Unri Press

Istiqomah,dkk. 2013. Sukses Uji Kompetensi guru. Jakarta: Dunia Cerdas.

Kemendiknas. 2010. Pembinaan Pendidikan Karakter. Jakata

Kunandar. 2007. Guru Profesional .Jakarta:Rajawali pers

Mudasir. 2011. Manajemen Kelas. Riau: Zanafa

Mulyasa. 2005. Menjadi Guru Profesional. Bandung: PT. Rosda Karya

Miarso.2008. Peningkatan Kualifikasi Guru dalam Perspektif teknologi Pendidikan. Jurnal Pendidikan Penabur No. 10/Tahun ke-7/Juni 2008.

NCES.2000. Monitoring School Quality:An Indicators Report. U.S. Departement of Education Research and Improvement.

Pekar, Jack P. 1995. Total Quality Management Guiding Principles For aplication.Philadelphia,PA

Sallis,. 2010. Manajemen Mutu Terpadu Pendidikan, IRCiSoD

Sugiyono, Prof.Dr.2012. Metode Penelitian Kuantitatif Kualitatif dan R\&D. bandung:Alfabeta.

Sagala, Syaiful. 2010. Manajemen Strategik dalam Peningkatan Mutu Pendidikan. Bandung:Alfabeta.

Sallis.Edward .2002. Total Quality management in Education, Third Edition. USA. Stylus Publishing Inc.

Seifert \& Sutton. 2009. Educational Psychology. Switzerland:The Saylor Foundation.

Sarjilah. 2015. Makalah "Makna Pengembangan Manusia Pada Pelatihan Guru". Yogyakarta.

Sirega r,EM. 2008. Implementasi Manajemen Mutu ISO 9001 dan Pengaruhnya Terhadap Kinerja di LPMP Propinsi Riau..Jakarta : Tesis PPs UNJ.

Tim Penyusun Kamus Besar Bahasa Indonesia., 1991. Kamus Besar Bahasa Indonesia. Jakarta:Balai Pustaka 


\section{JURNAL}

MANAJEMEN PENDIDIKAN

Vol. 5 No.1 Maret 2021: pp.1-10

PENELITIAN KUALITATIF e-ISSN: 2775-6904 | p-ISSN: 2502-9487

Uno, Hamzah.B. 2012. Profesi Kependidikan. Jakarta:Bumi Aksara.

Widoyoko. 2012. Teknik Penyusunan Instrumen Penelitian. Yoyakarta:Pustaka Pelajar.

http://www.duniapelajar.com/2014/08/04/pengertian-mutu-pendidikan-menurut-para-ahli. diakses 30 $\underline{\text { mei } 2015}$ 